\title{
TEXTO, DISCURSO, GÊNEROS TEXTUAIS E PRÁTICAS SOCIAIS NA SOCIEDADE CONTEMPORÂNEA: TRIBUTO A JOSÉ LUIZ MEURER
}

\author{
(Text, discourse, genres and social practices in contemporary \\ society: a tribute to José Luiz Meurer)
}

Viviane M. Heberle ${ }^{1}$ (Universidade Fedral de Santa Catarina/ CNPq)

\begin{abstract}
In this essay I pay a tribute to Prof. José Luiz Meurer, whose premature death occurred in October 24, 2009. First, I provide a brief account of his academic career, highlighting his achievements as a teacher and researcher. Then, I discuss the main theoretical and methodological issues he was concerned with, which are aligned with the purposes of the present journal Cadernos de Linguagem e Sociedade. More specifically, I discuss Prof. Meurer's understanding of the terms text, discourse, genre, social practices and his theoretical proposal for a social theory of context for text analysis in contemporary society, which he developed drawing mainly on genre studies, critical discourse analysis and systemic-functional grammar.
\end{abstract}

Key words: discourse; genre; social theory of context;

\section{RESUMO}

Neste ensaio presto uma homenagem ao Prof. José Luiz Meurer, cuja morte prematura ocorreu no dia 24 de outubro de 2009. Primeiramente apresento um breve relato de sua carreira acadêmica, enfatizando sua atuação como docente e pesquisador. A seguir, discuto as questões teóricas e metodológicas de seu interesse, que se alinham aos propósitos do presente periódico Cadernos de Linguagem e Sociedade. Mais especificamente, discuto a

1. Professora Associada III junto ao Curso de Letras/Inglês e ao Programa de PósGraduação em Letras/Inglês da UFSC, líder do grupo de pesquisa NUPDiscurso e Bolsista de Produtividade em Pesquisa do CNPq (Processo n. 305756/2008-7). Seus focos de interesse são multiletramento, linguagem e gênero social e ensino de língua, com base em estudos de multimodalidade, linguística sistêmico-funcional e análise crítica do discurso. 
visão do Prof. Meurer em relação aos termos texto, discurso, gênero textual, práticas sociais e sua proposta de uma teoria social do contexto para a análise de textos na contemporaneidade, que ele desenvolveu a partir de estudos em gêneros textuais, análise crítica do discurso e linguística sistêmico-funcional.

Palavras-chave: discurso, gênero textual; teoria social do contexto

\section{Introdução}

Fui convidada pela Editora-Chefe da Revista Cadernos de Linguagem e Sociedade, Profa. Dra. Denize Elena Garcia da Silva para escrever o presente ensaio sobre questões teóricas propostas pelo saudoso Prof. Dr. José Luiz Meurer, como forma de homenagem a quem foi um grande pesquisador brasileiro da linguagem, professor titular do curso de Letras/Inglês e do Programa de Pós-Graduação em Letras/Inglês e Literatura Correspondente (PPGI), da Universidade Federal de Santa Catarina. Inicialmente, traço um breve histórico da trajetória acadêmica do Prof. José Luiz para discutir, então, três focos importantes de seus estudos, a saber, estudos de texto e discurso e parâmetros de textualização; gêneros textuais e seu papel na formação de profissionais da linguagem e a sua proposta de uma teoria social do contexto para a análise de textos na sociedade contemporânea. Enfatizo a relevância que o Prof. Meurer atribuía ao componente social e crítico na interdependência entre linguagem e sociedade.

Entre as homenagens póstumas que o Prof. José Luiz recebeu, Barbara (2009:VII) destaca que o Prof. José Luiz "foi sempre pesquisador ativo e respeitado em várias áreas da Linguística Aplicada” e também menciona "sua participação, gerando e incentivando idéias e ações, sua presença amiga, alegre, otimista e colaboradora”. Em outra homenagem, Motta-Roth e Hendges (2010:7), ambas orientadas pelo Prof. Meurer, afirmam que como orientador o Prof. Meurer "foi sempre um leitor crítico e, ao mesmo tempo, encorajador" e "compartilhava uma energia intelectual inesgotável com seus orientandos e colegas, sempre no sentido da melhor prática, do embate intelectual leal e 
justo". Também Menezes (2010: 479) nos diz: "Em todos nós ficou a saudade e a sensação de perda do amigo e do acadêmico exemplar".

Em relação a sua trajetória acadêmica, o Prof. Meurer obteve seu título de mestre em Literatura pelo PPGI/UFSC. Tendo sido aprovado para cursar doutorado pela Universidade de Georgetown, nos Estados Unidos, ele inicialmente obteve outra titulação de mestre nessa mesma renomada instituição. Com seu diploma de doutor em Linguística pela Universidade de Georgetown, obtido em 1985, retornou à UFSC e a partir de então se dedicou ao aprimoramento de sua careira como docente e pesquisador. Como professor, várias vezes foi homenageado nas formaturas de Letras da UFSC e também orientou alunos de graduação (6), mestrado (17) e doutorado (17). Entre os seus orientandos de doutorado com perfis acadêmico-profissionais louváveis e atuantes em Linguística Aplicada, podemos citar as Profas. Lêda M. B. Tomitch (a primeira orientanda de mestrado e de doutorado do Prof. Meurer), Débora de C. Figueiredo, Adriana Kuerten Dellagnelo e Maria Ester Moritz (todas docentes da UFSC); Profas. Desirée Motta-Roth e Graciela R. Hendges (UFSM), Profa. Aleksandra Piasecka-Til (UFPR); Profs. Anderson de Souza, Carla L. Reichmann e Félix A. R. da Silva (UFPB); Maria Elizabeth da C. Gama (UNIVALI); Antonia Dilamar Araujo (UECE); Francisco O. Dourado Veloso (UFAC); e Philippe Humblé (Erasmus University College, Bélgica).

O Prof. Meurer também contribuiu para o desenvolvimento de estudos de doutorado-sanduíche a diversos doutorandos do PPGI na Universidade de Sidnei e também na Universidade de New South Wales em Sidnei, ambas especializadas em Linguística sistêmico-funcional . Outra conquista acadêmica foi o acordo de co-tutela entre o PPGI e o Departamento de Linguística da Universidade de Sidnei, que também já possibilitou estágios de estudos de doutorado a diversos alunos do PPGI.

Além de integrar diversas bancas de mestrado e doutorado e de comissões avaliadoras de concursos públicos para docentes de ensino superior, o Prof. Meurer foi também tutor do Grupo PET-Letras da UFSC, Coordenador Nacional dos PETS para a área de Linguística, 
Letras e Artes (de 1995 a 2001) e Coordenador do GT de Linguística Aplicada da ANPOLL (de 1998 a 2000).

Como pesquisador, sua atuação inicial referia-se aos estudos cognitivos de leitura (Meurer, 1985), mas já se percebia seu interesse pela investigação do texto e sua ligação com o contexto. Assim, gradualmente, ele se preocupava cada vez mais com estudos do texto e do discurso, área que o impulsionou a perseguir com afinco, sempre com um objetivo educacional. Desde essa época, já havia diálogos interdisciplinares com colegas tais como Angela Kleiman, Luiz Paulo da Moita Lopes, Maria Antonieta Alba Celani, Carmen Rosa Caldas-Coulthard, José Carlos Paes de Almeida, Hilário Bohn, John Robert Schmitz, Marilda Cavalcanti e Luiz Antonio Marcuschi, entre tantos outros.

A ligação com a LSF (Linguística Sistêmico-funcional), um dos principais arcabouços teóricos utilizados por Meurer, teve início no Programa de Pós-Graduação em Letras/Inglês da UFSC (PPGI/ UFSC), através dos professores Rosa Konder, Malcolm Coulthard (naquela época na Universidade de Birmingham, Inglaterra) e Carmen Rosa Caldas Coulthard.Também em seus períodos de pós-doutorado na Universidade de Birmingham (Inglaterra) em 1993-1994 e mais tarde (2003-2004) na Universidade Macquarie (Austrália), o Prof. Meurer teve a oportunidade de aprofundar seus conhecimentos na área de LSF e análise crítica do discurso.

Ele também exerceu o cargo de Coordenador do PPGI por três mandatos, foi bolsista de Produtividade em Pesquisa do CNPq e líder do Núcleo de Pesquisa Texto, Discurso e Práticas Sociais da UFSC (cadastrado no CNPq), além de ter atuado como membro de comissões editoriais de periódicos nacionais e internacionais e também na CAPES e CNPq. Destaque também deve ser dado à organização de dois importantes eventos internacionais realizados na UFSC, sob sua coordenação: Estudos da Narrativa, em 1987 e mais recentemente o IV Congresso da ALSFAL (Associação de Linguística SistêmicoFuncional da América Latina), em 2008.

Meurer também participou como palestrante e/ou apresentador de comunicações em inúmeros eventos nacionais, tais como o INPLA, SIGET, CBLA, ENPULI, CELSUL, GEL, GELNE, GELCO e 
eventos da ANPOLL, ABRALIN e SBPC. Participou de congressos internacionais como o TESOL em Chicago (1996), o da AILA em Tóquio (1999), os congressos da Associação Britânica de Linguística Aplicada (1997) e da Associação de Análise de Diálogo (1999), ambos em Birmingham, Inglaterra, os Congressos Internacionais de Linguística Sistêmico-funcional em Cardiff (1998), Ottawa (2001), São Paulo (2006) e em Odense (2007), e os congressos da ALSFAL em Concepción (2005) e Puebla (2007).

Entre suas publicações mais relevantes, além de vários artigos em periódicos indexados, destacam-se: a) artigos em livros internacionais (Aspects of a model of writing: Translation as text production, 1996 e Role prescriptions, social practices, and social structures: A sociological basis for the contextualisation of analysis in SFG and CDA, 2004); b) os livros Aspects of language in self-help counselling (1998), Parâmetros de Textualização (1997) e Gêneros textuais e práticas discursivas: subsídios para o ensino da linguagem (ambos organizados com D. Motta-Roth), Gêneros: teorias, métodos, debates (organizado com A. Bonini e D. Motta-Roth, 2005), já na segunda edição, e Introdução à Análise do discurso (em co-autoria com A. Dellagnelo), além de organizações de edições temáticas na revista Ilha do Desterro (1992; 2004; 2006).

Após esse breve relato da trajetória acadêmica do Prof. Meurer, apresento a seguir uma pequena seleção de algumas das suas reflexões.

\section{Texto, discurso e parâmetros de textualização}

Duas grandes preocupações do Prof. Meurer sempre foram a relação intrínseca entre texto, discurso e o contexto sociocultural onde o texto ocorre e a necessidade de se examinar no texto questões referentes aos parâmetros de textualização, ou seja a questões lexicogramaticais e de organização retórica de textos (Meurer, 1996; 1997a).

Encontramos uma definição de texto em Meurer (1997b:758), para quem "textos são trechos de linguagem em uso, utilizados tanto em forma oral como escrita, que se caracterizam por sua determinada 
organização linguística e uma determinada função social, num determinado contexto histórico-social” .

Com base em Kress (1989), Foucault (1972) e Fairclough (1992), Meurer (1997a:16) enfatiza que cada ser humano encontra-se em diferentes redes de relações sociais e que "[a]s práticas, os valores, os significados, as demandas, proibições e permissões existentes entre os diferentes agrupamentos sociais, ... exercem influência direta sobre os indivíduos que convivem dentro desses grupos”. Acrescenta ainda que essas práticas, valores e significados "são expressos e articulados em grande parte através da linguagem”. Assim, Meurer define texto e discurso:

O discurso é o conjunto de afirmações que, articuladas através da linguagem, expressam os valores e significados das diferentes instituições; o texto é a realização lingüística na qual se manifesta o discurso. Enquanto o texto é uma entidade física, a produção lingüística de um ou mais indivíduos, o discurso é o conjunto de princípios, valores e significados 'por trás' do texto. Todo discurso é investido de ideologias, isto é, maneiras específicas de conceber a realidade. Além disso, todo discurso é também reflexo de uma certa hegemonia, isto é, exercício de poder e domínio de uns sobre outros. A partir dessas características, o discurso organiza o texto e até mesmo estabelece como o texto poderá ser, quais tópicos, objetos ou processos serão abordados e de que maneira o texto deverá ser organizado. (MEURER, 1997a:16).

A partir da análise crítica do discurso segundo Fairclough (1989, 1992), uma das principais perspectivas teórico-metodológicas que serviram de base para as reflexões do Prof. Meurer, texto referese a uma das dimensões de análise. Meurer (2007a: 96) explica: "ao analisar o evento comunicativo como texto, Fairclough privilegia a descrição do léxico, as opções gramaticais, a coesão e a estrutura do texto". E continua: "o discurso tem um poder construtivo tríplice: (1) produz e reproduz conhecimentos e crenças por meio de diferentes modos de representar a realidade; (2) estabelece relações sociais; e (3) cria, reforça ou reconstitui identidades (Fairclough, 1992). (MEURER, 2002a: 18). 
Assim, Meurer (2000b:168-169) afirma que "a construção diária da nossa própria narrativa pessoal como ser humano é em grande parte construída e determinada pelos textos que produzimos e a que estamos expostos".

Em seu modelo sociocognitivo de produção textual, Meurer (1993; 1997a) discute a questão de parâmetros de textualização, que inclui aspectos relativos ao objetivo do texto, ao público-alvo, ao gênero textual, à organização retórica e às relações oracionais (Winter, 1986), ao contexto sociocultural onde o texto ocorre, à organização coesiva do texto como um todo, à coerência, entre outros. Para ilustrar alguns desses aspectos de textualização, relacionados por Meurer, refiro-me ao seu trabalho sobre livros de autoajuda (1998; 2002b), que contém quatro componentes semânticos típicos de textos exortativos: a) um problema, ou problemas, a ser (em) resolvido(s); b) credenciais do autor que propõe soluções; c) comandos ou orações imperativas, instigando indivíduos a modificar sua conduta; d) motivação, incentivando os leitores a aceitar a autoridade e os comandos do autor. Com um objetivo de investigação crítica, ele continua, questionando sobre esses quatro macro-componentes, que apresentam "soluções baseadas no individualismo, alheias a estruturas sociais, hegemonias e ideologias mais abrangentes".

Para adotar essa investigação crítica, ele sugere: " creio ser importante discutir tais questões a partir de uma perspectiva crítica já que, como um importante tipo de cultura de massa, livros de autoajuda podem contribuir discursivamente para a manutenção ou para a mudança de como seus leitores percebem a si próprios, afetando estruturações sociais atuais (Meurer, 2002b:222). As noções de texto e discurso propostas por Meurer enquadram-se na sua proposta de análise crítica de gêneros textuais, sobre a qual discorro a seguir.

\section{Por uma análise crítica de gêneros textuais}

Como estudioso de gêneros textuais, Meurer reforçava a necessidade de um aprofundamento no estudo de gêneros textuais 
e sua ligação com ações humanas, com as práticas sociais. Para discutir o projeto de uma análise crítica de gêneros textuais, Meurer (2005) propunha a integração de quatro perspectivas de pesquisa em linguagem, a saber, a linguística sistêmico-funcional, a análise crítica do discurso, estudos de gêneros e teorizações sobre o componente sociológico da linguagem, perspectivas essas que o acompanharam até o final de sua carreira.

Inicialmente, sua definição de gênero textual era: "tipo específico de texto de qualquer natureza, literário ou não, oral ou escrito, formal ou informal, caracterizado e reconhecido por função específica e organização retórica mais ou menos típica, e pelo(s) contexto(s) onde é utilizado" (Meurer, 2002a:18). Mais tarde, com suas incursões por estudos de multimodalidade e também levando em consideração os quatro sistemas (físico, biológico, social e semiótico), conforme Halliday e Matthiessen (1999, in Butt et al, 2004), Meurer complementa essa definição sugerindo que gêneros textuais são atividades semióticas, isto é, de produção e consumo de significados.

Sua preocupação com gêneros textuais teve início na década de 1990, através de teóricos como Swales (1990), Miller (1984) e Martin (1984). Ao enfatizar o papel dos gêneros textuais para a formação dos profissionais da linguagem, Meurer (2000b: 152-153) nos diz:

Os conhecimentos que os seres humanos possuem, sua identidade, seus relacionamentos sociais e sua própria vida são em grande parte determinados pelos gêneros textuais a que estão expostos, que produzem e 'consomem'. Pode-se mesmo afirmar que a própria cultura de um país, como um todo, é caracterizada pelo conjunto dos gêneros textuais produzidos e utilizados pelos seus cidadãos. Consequentemente, a investigação e o ensino sistemáticos dos diversos tipos de textos em uso - escritos por quem, para que fins, como, em que ambientes, com que grau de transparência ou de camuflagem hegemônica e ideológica - são essenciais para a formação dos profissionais responsáveis pelo ensino da linguagem no país.

Entre as questões sugeridas por Meurer para a investigação de gêneros textuais, pode-se citar tanto aspectos linguísticos (os itens lexicogramaticais, estrutura textual, coesão, coerência e outros 
parâmetros de textualização) quanto contextuais e sociais (a função ou papel social que os gêneros desempenham, formas de poder em relação à produção de um gênero específico, questões de ideologia e as práticas sociais associadas ao uso de diferentes gêneros, por exemplo).

Meurer (2000a) também faz uma clara distinção entre gêneros textuais e modalidades retóricas:

Enquanto os gêneros textuais constituem tipos específicos de textos, as modalidades retóricas constituem as estruturas e as funções textuais tradicionalmente reconhecidas como narrativas, descritivas, argumentativas, procedimentais e exortativas (Longacre 1983, 1992; Virtanen 1992). Essas modalidades são estratégias utilizadas para organizar a linguagem, muitas vezes independentemente das funções comunicativas associadas aos gêneros textuais específicos. Assim, com freqüência, um único texto contém mais do que uma modalidade retórica. Por exemplo, uma carta pessoal pode conter trechos narrativos (um histórico do que a pessoa que escreve tem feito recentemente), trechos descritivos (como é o lugar onde está morando), trechos procedimentais (instruções para alguém enviar-lhe dinheiro), trechos exortativos (incentivando um irmão, digamos, a uma determinada conduta) e mesmo trechos argumentativos (defendendo uma determinada perspectiva ou visão de alguma coisa). Enquanto as modalidades retóricas constituem um número extremamente reduzido, os gêneros textuais existem em número muito maior. Existem tantos gêneros textuais quantas as situações sociais convencionais onde são usados em suas funções também convencionais. (Meurer, 2000a:150)

Defensor do uso do termo gênero textual (em oposição a gênero discursivo), Meurer sempre direcionava suas reflexões teóricas para que professores e alunos pudessem usufruir do conhecimento dos conceitos de texto, discurso, gêneros textuais e práticas sociais numa relação bidirecional entre texto e contexto social. A partir desses conceitos, enfatizava que o estudo da linguagem nas escolas deveria ir além de nomenclatura gramatical e estudo de formas somente para a análise de textos como linguagem em uso, em contexto, como ação humana ou prática social (Meurer, 2002c; Heberle e Meurer, 2006; 2007). Na última parte deste ensaio, sucintamente apresento sua proposta de uma teoria social do contexto. 


\section{Por uma teoria social do contexto para a análise de textos e discursos}

Tendo em vista as interrelações entre texto e contexto, entre linguagem e estruturas sociais e levando em conta as quatro perspectivas teóricas já mencionadas, com a incorporação das noções de texto, discurso, gêneros textuais e práticas sociais, Meurer (2008) propôs uma teoria social do contexto para a análise de textos e discursos na sociedade contemporânea, Duas outras influências importantes para a proposta dessa teoria são: 1) a afirmação de Halliday (1978) de que as considerações sobre questões sociais deveriam ter uma base sociológica; 2) a teoria de estruturação segundo o sociólogo inglês Anthony Giddens (1984; 1991). De acordo com Meurer (2006:170):

A teoria da estruturação se propõe a explicar o fluxo da vida social como estando em estruturação constante, em um processo complexo que se dá com o envolvimento simultâneo das três dimensões sociais...

(a) práticas sociais nas quais (b) indivíduos agem de acordo - ou não - com prescrições de papéis identitários e em (c) estruturas sociais existentes caracterizadas por regras e recursos.

Em relação a essas três dimensões, Meurer (2006: 170-171) explica que enquanto as práticas sociais são "as atividades habituais que as pessoas realizam ao conduzir a vida social nos mais variados contextos”, as identidades ou as prescrições de papéis sociais são "as prerrogativas e as obrigações - ou direitos e deveres - que cada indivíduo tem ao participar das práticas sociais". Já as regras e recursos, não necessariamente oficialmente impostos, referem-se às rotinas, às normas, aos regulamentos e sanções das pessoas em suas práticas sociais.

O projeto (de ordem teórico-metodológica) inacabado do Prof. José Luiz (Meurer, 2008) visava construir e testar uma teoria social do contexto para ser aplicada a gêneros textuais em práticas sociais contemporâneas. As perguntas gerais da pesquisa eram: que elementos de cunho sociológico devem ser integrados a uma teoria do contexto de forma a permitir a descrição e interpretação sistemáticas 
da interdependência entre o contexto e o uso da linguagem? Como podemos mostrar de forma sistemática que um texto é influenciado ou determinado pelo contexto, ao mesmo tempo em que o influencia ou determina?

Como linguistas aplicados ou analistas do discurso, talvez possamos nos debruçar sobre essas perguntas específicas e tentar respondê-las. Ou quem sabe outras reflexões do Prof. Meurer possam servir de inspiração para trabalhos futuros nessas áreas do saber. Para $\mathrm{mim}$, que tive o privilégio de ter convivido com ele por quase vinte anos, ficam a saudade profunda de um grande companheiro e a falta intensa de sua notável interlocução acadêmica.

Convidada especial para este volume Enviado em: junho de 2011 heberle@cce.ufsc.br

\section{Referências bibliográficas}

BARBARA, L. Homenagem póstuma a José Luiz Meurer. Delta, 25 (especial): VII-XI, 2009.

BUTT, D; Lukin, A; MATTHIESSEN, C. Grammar: the first covert operation of war. Discourse \& Society, Vol 15(2-3): 267-290, 2004.

FAIRCLOUGH, N. Language and power. London: Longman, 1989. . Language and social change. Cambridge: Polity Press, 1992.

FOUCAULT, M. The archeology of knowledge. London: Tavistock Publications, 1972.

GIDDENS, A. The constitution of society. Cambridge: Polity Press, 1984. . Modernity and Self-Identity. Cambridge: Polity Press, 1991.

HALLIDAY, M.A.K. Language as social semiotic. London : Edward Arnold, 1978.

HEBERLE, V. M. (Org.); Meurer, J. L. (Org.). Ilha do Desterro n. 46: Systemic functional linguistics in action. Florianopolis: Editora da UFSC, 2004. 
- Formação de professores de línguas estrangeiras: considerações a partir da linguística aplicada, linguística sistêmico-funcional e análise crítica do discurso. IN: S. E. Oliveira; J. F. dos Santos (Orgs.). Mosaico de Linguagens. Campinas: Pontes, 2006, p. 91-98.

. Aspects of visual analysis for the EFL class. In: I Congresso Internacional da ABRAPUI, 2007, Belo Horizonte. Anais do I Congresso Internacional da ABRAPUI. Belo Horizonte : ABRAPUI/UFMG/FAPEMIG, 2007, p. 01-11.

KRESS, G. Linguistic processes in sociocultural pratice. Oxford University Press, 1989.

LONGACRE, R. E. The grammar of discourse. New York: Plenum Press, 1983.

. 1992. The discourse strategy of an appeals letter. Discourse description: Diverse linguistic analysis of a fund-raising text. IN: W. C. Mann; S. A. Thompson (Orgs.), Amsterdam/Philadelphia: John Benjamins. 1992, pp. 108-130.

MARTIN, J. Language, register and genre. In Children writing: Reader ECT412. Victoria: Deakin University, 1984, p 21-30.

MENEZES, V. (Org) Tributo a José Luiz Meurer. Revista Brasileira de Linguística Aplicada, Belo Horizonte, v. 10, n. 2: 479-494, 2010.

MEURER, J. L. Reading Comprehension in L1 and L2: Exploring Text Sctructure,

Schemata, and Advance Organizers. PhD thesis. Georgetown University. Michigan: UMI, 1985.

. (Org.) Ilha do Desterro n. 27: Text Analysis/Análise de Texto. Florianópolis: PGI/UFSC, 1992.

. Aspectos do processo de produção de textos escritos. Trabalhos de Linguística Aplicada, 21:37-48, 1993.

. Aspects of a model of writing: Translation as text production. In: M. Coulthard; P. O. de Baubeta (eds.). The knowledges of the translator. Wales, UK: The Edwin Mellen Press, 1996, p. 67-90.

. Esboço de um modelo de produção de textos. In: J.L. Meurer; D. Motta-Roth (Org.) Parâmetros de textualização. Santa Maria: Ed. Da UFSM, 1997a, p.13-28.

. Introdução a artigos acadêmicos de pesquisadores brasileiros: aspectos de sua textualização. Florianópolis: Anais do $1^{0}$ CELSUL, vol 2, 1997b, p. 758-768. 
. Aspects of language in self-help counselling. Florianópolis: PósGraduação em Letras/Inglês, 1998.

. O conhecimento de gêneros textuais e a formação do profissional da linguagem. In: M. B. M. Fortkamp; L. M. B. Tomitch. (Orgs.). Aspectos da Linguística Aplicada. Estudos em homenagem ao Professor Hilário Inácio Bohn. Florianópolis: Insular, 2000a, p. 149-166.

. O trabalho de leitura crítica: recompondo representações, relações e identidades sociais. L. Tomitch (Org.). Ilha do Desterro (UFSC) Florianópolis, v. 1, n. 38:155-171, 2000b.

. Uma dimensão crítica de gêneros textuais. In: J.L. Meurer; D. MottaRoth (Orgs.). Gêneros textuais e práticas discursivas:subsídios para o ensino da linguagem. Bauru: EDUSC, 2002a, p. 17-29.

. "Aspectos do gênero 'livro de auto-ajuda': uma análise crítica”. Caderno de resumos do 50 GEL USP/SP, 2002b, p. 222.

. Reflexões sobre o ensino: três perguntas não mistificadoras que você pode aplicar aos textos que traz para a sala de aula.. In: M. J. D. Costa; M.L. Zipser; M.E. Zanatta; A. Mendes. (Orgs.). Línguas: ensino e ações. Florianópolis: NUSPPLE/DLLE/CCE/UFSC, 2002c, p. 133-139.

. Role prescriptions, social practices, and social structures: A sociological basis for the contextualisation of analysis in SFG and CDA. In: YOUNG, L. \& HARRISON, C. (Eds.). Systemic functional linguistics and critical discourse analysis. Studies in social change. London/New York: Continuum, 2004, p. 85-99.

. Análise crítica de gêneros textuais: texto e contexto a partir da linguística sistêmico-funcional com ênfase no componente sociológico da linguagem. Projeto submetido ao CNPq para Bolsa de Produtividade em Pesquisa, 2005.

. Integrando estudos de gêneros textuais ao contexto da cultura. In: A. Karwoski et al (Org.) Gêneros textuais: reflexões e ensino. 2 ed. Rio de Janeiro: Editora Lucerna, 2006, p. 165-185.

. Gêneros textuais na análise crítica de Fairclough. In J.L. Meurer; A. Bonini; D. Motta-Roth (Orgs.). Gêneros: teorias, métodos, debates. $2^{\mathrm{a}}$. ed. São Paulo: Parábola, 2007, p. 81-106.

. Uma teoria social do contexto para a análise de textos e discursos na contemporaneidade. Projeto submetido ao CNPq para Bolsa de Produtividade em Pesquisa, 2008. 
MEURER, J. L. (Org.); Motta-Roth, D (Org.) Parâmetros de textualização. Santa Maria: Ed. da UFSM, 1997.

. Gêneros textuais e práticas discursivas: subsídios para o ensino da linguagem. Bauru: EDUSC, 2002.

MEURER, J.L. (Org.); Bonini, A. (Org); Motta-Roth, D. (Org). Gêneros: teorias, métodos, debates. Parábola Editorial, 2005.

MEURER, J. L. (Org.); Nanri, K. (Org); Sasaki, M (Org); Yasumoto, S. (Org). Ilha do Desterro n. 50. Florianópolis: Editora da UFSC, 2006.

MEURER, J.L.; Dellagnelo, A. Introdução à análise do discurso. Florianópolis: Editora da UFSC, 2008.

MILLER, C. R. Genre as social action. Quarterly Journal of Speech, 70: 151176, 1984.

MOTTA-ROTH, D.; Hendges, G. Apresentação e homenagem. Letras, v.20, 40:7-8, 2010.

SWALES, J. (1990). Genre analysis: English in academic and research settings. Cambridge: Cambridge University Press.

VIRTANEN, E. Issues of text typology: Narrative: A 'basic' type of text? Text, 12(2): 293-310, 1992.

WINTER, E. Clause relations as information structure: Two basic text structures in English. In: M. Coulthard (ed) Talking about Text. Discourse analysis monographs, n. 13. ELR: University of Birmingham, 1986, p. 88108. 